\title{
Knowledge Management a way to gain a competitive advantage in firms (evidence of manufacturing companies)
}

\author{
Bahram Meihami ${ }^{1}$, Hussein Meihami ${ }^{2}$ \\ ${ }^{1}$ Department of Accounting, Ghorveh Branch, Islamic Azad University, Ghorveh, Iran \\ ${ }^{2}$ Department of English Language Teaching, Ghorveh Branch, Islamic Azad University, Ghorveh, Iran \\ E-mail address: meyhami4@gmail.com
}

\begin{abstract}
Knowledge as the basis of competition is the most important factor and the knowledge, innovations also Technology and knowledge based companies as the most important factor for survival is known. Knowledge Process Entrepreneurship, the creation of knowledge and the conversion of products and services through innovation. The most basic feature of Intelligent Organizations twenty-first century, the emphasis on knowledge and information. Unlike previous organizations, organizations advanced technologies today, require Acquisition, management and exploitation of knowledge and information to improve efficiency, manage and track Variations are endless. Knowledge is a powerful tool that can change the world And innovations made possible. Knowledge management is an interdisciplinary business model with all aspects of knowledge creation, Coding, sharing and using knowledge to enhance learning and innovation in the context of the company and Is working. This study developed a questionnaire and send it to companies located in the industrial town managers found that knowledge management has an impact on the surface of the competitive advantage's Knowledge management and competitive advantage, Innovation , Organizational performance, Customer satisfaction, The study variables were. Ranged the in 2,013th were tested. The results indicate that Knowledge management has made a significant competitive advantage.
\end{abstract}

Keywords: Knowledge Management; Competitive Advantage; Innovation; Customer satisfaction; Organizational performance

\section{INTRODUCTION}

\section{1.What Is Knowledge?}

Most definitions and explanations of knowledge seem to cover the same vocabulary, concepts and words. Rather than provide a standard definition, the paper addresses the general themes and fundamentals that have become evident in recent years.

- Knowledge goes through a process of sharing tacit with tacit knowledge, tacit to explicit, explicit leverage, and explicit back to tacit.

- Knowledge can be created and tested. 
- Knowledge can be distinguished from data and information.

- Explicit knowledge is usually filtered, stored, retrieved and dispersed across the organisation.

- A culture that does not foster and reward the sharing of knowledge cannot expect technology to solve its problems (Srinivas 2000).

\subsection{KM definition}

$\mathrm{KM}$ is often viewed as multidimensional and multidisciplinary concept. There are many definitions of KM in the literature, thus comparisons must be made to know the focus by each author. Some of the focuses are highlighted below. Professor Michael Sutton (2008) of the Gore School of Business at Westminster College reported at the ICKM (International Conference on Knowledge Management) meeting in 2008 that he had assembled a library of more than 100 of them (Mclnerney C. and Koeing M., 2009). Three definitions of KM ones are presented here. At the very beginning of the KM movement, Davenport (1994) offered the following: "knowledge management is the process of capturing, distributing, and effectively using knowledge". This definition has the virtue of being simple, stark, and to the point. A few years later, the Gartner Group created another definition of KM, which is perhaps the most frequently cited (Duhon, 1998): "A discipline that promotes an integrated approach to identifying, capturing, evaluating, retrieving, and sharing all of an enterprise's information assets. These assets may include databases, documents, policies, procedures, and previously un-captured expertise and experience in individual workers".

\section{3. The Knowledge Transformation Process}

As stated earlier, knowledge goes through a transformation process, which can be facilitated through the utilisation of Decision Support Systems (DSS), Artificial Intelligence (AI). The paper covers the main area of focus, the explication of knowledge, with further detail of this transformation process to be found in the following reference (Nemati, Steiger et al. 2002). DSS are IT and software specifically designed to help people at all levels of the company, below the executive level, make decisions. DSS can play an important role in the transformation process of explicating knowledge, for example, through the specification of mathematical modelling. Specifically, the goal of these models, and of the decision variables, must be explicitly articulated by the decision-maker. Furthermore, the decision maker must also explicitly articulate the model constraints. This specification of explicit knowledge "represents the tacit knowledge the worker has developed over time, within the decisionmaking environment" (Nemati, Steiger et al. 2002). DSS can further enhance the explication of knowledge by "eliciting one or more what-if cases, representing areas the knowledge worker would like to investigate" (Nemati, Steiger et al. 2002). In effect, the tacit knowledge of historical decisions is transformed into explicit form, to be shared and leveraged for improved decision making. Once this knowledge has been transformed and stored, it can be leveraged by making it available to others when and where they need it. (Nemati, Steiger et al. 2002) suggests that "explicit knowledge stored in the form of instances of a mathematical model (what-if cases) can be leveraged via deductive and/or inductive model analysis systems". Model-specific knowledge is applied to a single instance of a model, addressing such questions as "why is this the solution?," "why do the solutions to two model instances differ so much?". DSS can also help workers to learn, i.e. the process of converting explicit knowledge to implicit knowledge. Known as internalisation, this process involves the "identifying bodies of knowledge relevant to the particular user's needs" (Warkentin, 
Sugumaran et al. 2001). It involves extracting knowledge and filtering it to match a particular problem against the body of knowledge. Internalising explicit and/or new knowledge may arise through a decisionmaker modifying his/her internal mental model that is used as his/her performance guide for a specified situation (Nemati, Steiger et al. 2002).

\section{KM PROCESSES}

We earlier defined knowledge management as performing the activities involved in discovering, capturing, sharing, and applying knowledge so as to enhance, a cost-effective fashion, the impact of knowledge on the unit's goal achievement. Thus, knowledge management relies on four main kinds of KM processes. As shown in Figure 2, these include the processes through which knowledge is discovered or captured. It also includes the processes through which this knowledge is shared and applied. These four KM processes are supported by a set of seven KM sub-processes, as shown above with one Sub-process socialization - supporting two KM processes (discovery and sharing). Of the seven KM subprocesses, four are based on Nonaka (1994). Focusing on the ways in which knowledge is converted through the interaction between tacit and explicit knowledge, Nonaka identified four ways of managing knowledge:

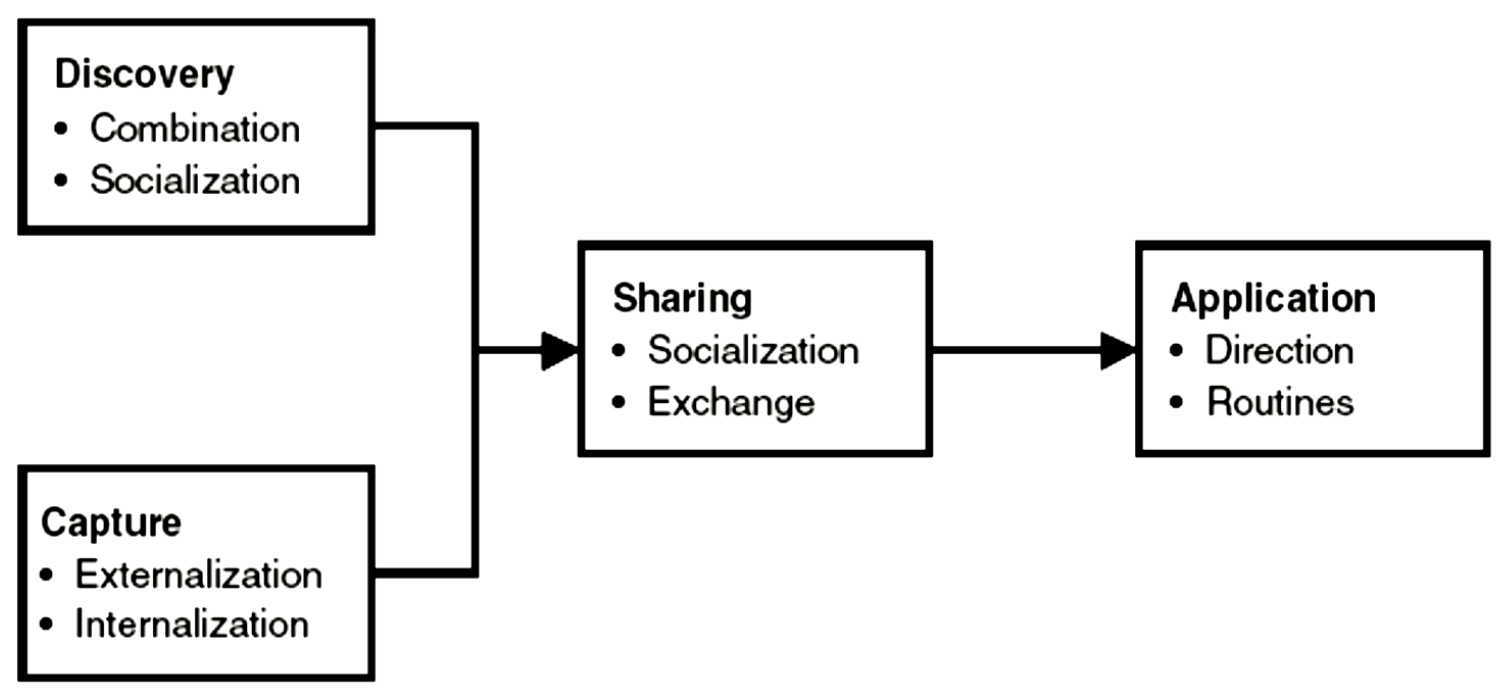

Figure 1. KM processes (Jihene Chebbi Ghannay and Zeineb Ben Ammar Mamlouk, 2012).

\section{1. The Knowledge Management Processes Cycle}

Figure 2 is a process cycle model of KM. Such cycle models provide a useful way to organize one's thinking about KM processes. There have been numerous KM processes cycle models that describe the relationships of the key processes of KM, ranging from Davenport and Prusak's (2000) 3-stage model ("Generate, Codify/Coordinate, Transfer") to Ward and Aurum's (2004) 7-stage (“Create, Acquire, Identify, Adapt, Organize, Distribute, Apply”).

The process cycle model of Fig. 2 is particularly valuable in that it uses the generally accepted terminology of KM and makes use of alternative paths in order to make important distinctions. The various activities listed as bullet-points under some of the major phases are 
meant to be illustrative and not necessarily definitional. The model of Fig. 2 shows that the initiation of the KM cycle involves either the creation or the acquisition of knowledge by an organization. Knowledge creation involves developing new knowledge or replacing existing knowledge with new content (Nonaka, 1994). The focus of this is usually on knowledge creation inside the boundary of the firm or in conjunction with partners. The four bullet points under "Creation" refer to Nonaka's (1994) four modes of knowledge creation socialization (the conversion of tacit knowledge to new tacit knowledge through social interactions and shared experiences), combination (creating new explicit knowledge by merging, categorizing, and synthesizing existing explicit knowledge), externalization (converting tacit knowledge to new explicit knowledge) and internalization (the creation of new tacit knowledge from explicit knowledge). Illustrative of these four modes respectively are apprenticeships, literature survey reports, "lessons learned" repositories and individual or group learning through discussions. In contrast to knowledge creation, knowledge acquisition involves the search for, recognition of, and assimilation of potentially valuable knowledge, often from outside the organization (Huber, 1991).

The bullet points under "Acquisition" illustrate some processes for acquiring knowledge from external sources - searching (as on the Internet) (Menon and Pfeffer, 2003), sourcing (selecting the source to use) (King and Lekse, 2006) and grafting (adding an individual who possesses desired knowledge to the organization) (Huber, 1991). After new knowledge is created or acquired, KM mechanisms should be in place to prepare it to be entered into the organization's memory in a manner that maximizes its impact and longterm reusability. Knowledge refinement refers to the processes and mechanisms that are used to select, filter, purify and optimize knowledge for inclusion in various storage media.Under "Refinement" in the figure, the bullet points suggest that tacit, or implicit, knowledge must be explicated, codified, organized into an appropriate format and evaluated according to a set of criteria for inclusion into the organization's formal memory. Of course, explicit knowledge needs only to be formatted, evaluated, and selected. Of the various steps that are involved in doing so, "culling" refers to identifying the most significant exemplars in an emerging collection; "organizing" refers to identifying recurrent themes and linking individual knowledge items to the themes and "distilling" is creating a synopsis or set of pointers (McDonald and Ackerman, 1997).

Organizational memory includes knowledge stored in the minds of organizational participants, that held in electronic repositories, that which has been acquired and retained by groups or teams and that which is embedded in the business's processes, products or services and its relationships with customers, partners and suppliers (Cross and Baird, 2000). As shown in the figure, in order for knowledge to have wide organizational impact, it usually must be either transferred or shared. Transfer and sharing may be conceptualized as two ends of a continuum. Transfer involves the focused and purposeful communication of knowledge from a sender to a known receiver (King, 2006a). Sharing is less-focused dissemination, such as through a repository, to people who are often unknown to the contributor (King, 2006). Many of the points on the hypothetical continuum involve some combination of the two processes and both processes may involve individuals, groups or organizations as either senders or receivers, or both. Once knowledge is transferred to, or shared with, others, it may be utilized through elaboration (the development of different interpretations), infusion (the identification of underlying issues), and thoroughness (the development of multiple understandings by different individuals or groups) (King and Ko, 2001) in order to be helpful in facilitating innovation, collective learning, individual learning, and/or collaborative problem solving (King, 2005). It may also be embedded in the practices, systems, products 
and relationships of the organization through the creation of knowledge-intensive organizational capabilities (Levitt and March, 1988).

\section{2. Organizational Learning}

There are various ways to conceptualize the relationship between knowledge management and organizational learning. Easterby-Smith and Lyles (2003) consider OL to focus on the process, and KM to focus on the content, of the knowledge that an organization acquires, creates, processes and eventually uses.Another way to conceptualize the relationship between the two areas is to view OL as the goal of KM. By motivating the creation, dissemination and application of knowledge, KM initiatives pay off by helping the organization embed knowledge into organizational processes so that it can continuously improve its practices and behaviors and pursue the achievement of its goals. From this perspective, organizational learning is one of the important ways in which the organization can sustainably improve its utilization of knowledge. Indeed, Dixon (1994), in describing an "organizational learning cycle," suggested that "accumulated knowledge... is of less significance than the processes needed to continuously revise or create knowledge" (p. 6). These processes are closely related to the notion of "continuous improvement" through which an organization continuously identifies, implements and institutionalizes improvements. The improvements are embedded in the organization through routines that may be written policies, prescribed machine settings, quality control limits or "best practices" for dealing with frequently occurring circumstances.

\section{3. The Basics of Knowledge Management and Organizational Learning Knowledge}

Knowledge is often defined as a "justified personal belief". There are many taxonomies that specify various kinds of knowledge. The most fundamental distinction is between "tacit" and "explicit" knowledge. Tacit knowledge inhabits the minds of people and is (depending on one's interpretation of Polanyi's (1966) definition) either impossible, or difficult, to articulate. Most knowledge is initially tacit in nature; it is laboriously developed over a long period of time through trial and error, and it is underutilized because "the organization does not know what it knows" (O’Dell and Grayson, 1998, p. 154). Some knowledge is embedded in business processes, activities, and relationships that have been created over time through the implementation of a continuing series of improvements. Explicit knowledge exists in the form of words, sentences, documents, organized data, computer programs and in other explicit forms. If one accepts the useful "difficult-to-articulate" concept of tacit knowledge, a fundamental problem of KM is to explicate tacit knowledge and then to make it available for use by others. One can also distinguish among "know what," "know how" and "know why" levels of knowledge. "Know what," knowledge specifies what action to take when one is presented with a set of stimuli. For instance, a salesperson who has been trained to know which product is best suited for various situations has a "know-what" level of knowledge.

The next higher level of knowledge is "know-how" - i.e., knowing how to decide on an appropriate response to a stimulus. Such knowledge is required when the simple programmable relationships between stimuli and responses, which are the essence of "knowwhat" knowledge, are inadequate. This might be the case, for instance, when there is considerable "noise" in symptomatic information so that the direct link between symptoms and a medical diagnosis is uncertain. "Know how"-type knowledge permits a professional to determine which treatment or action is best, even in the presence of significant noise. The 
highest level of knowledge is "know-why" knowledge. At this level, an individual has a deep understanding of causal relationships, interactive effects and the uncertainty levels associated with observed stimuli or symptoms. This will usually involve an understanding of underlying theory and/or a range of experience that includes many instances of anomalies, interaction effects, and exceptions to the norms and conventional wisdom of an area.

\section{4. Knowledge Management Systems}

Knowledge management systems (KMS) are applications of the organization's computer-based communications and information systems (CIS) to support the various KM processes. They are typically not technologically distinct from the CIS, but involve databases, such as "lessons learned" repositories, and directories and networks, such as those designed to put organizational participants in contact with recognized experts in a variety of topic areas. A significant difference between many knowledge management systems and the organization's CIS is that the KMS may be less automated in that they may require human activity in their operation. While information systems typically require that humans make choices in the design phase and then operate automatically, KMS sometimes involve human participation in the operation phase. For instance, when a sales database is designed, people must decide on its content and structure; in its operational phase, it works automatically. When a "lessons learned" knowledge repository is created, people must make all of the same design choices, but they must also participate in its operational phase since each knowledge unit that is submitted for inclusion is unique and must be assessed for its relevance and important.

\section{5. e-Knowledge Networks for Business Improvement}

We will discuss one long-term alliance, suggested by Warkentin (Warkentin, Sugumaran et al. 2001), as a trend likely to develop from implementing strategic eknowledge networks in the context of supply chain. The supply chain process involves organisations acquiring resources and providing goods or services, (Johnson, Scholes 1999). Progressive supply chain management aims to improve the co-ordination "across the supply chain to create value for customers, while increasing the profitability of every link in the chain" (Warkentin, Sugumaran et al. 2001). It is this co-ordination aspect that addresses the role of shared knowledge, enabling the analysis and management of all supply change activities. In other words according to Choi et al. (Choi, Budny et al. 2004) the supply chain involving knowledge is referred to as knowledge supply chain and in this context they define knowledge as technologies, inventions and know-how that helps businesses bring products to markets. The material flow is the physical flow of material and the knowledge flow is like the flow of technique that connects the parts together. Figure 1 illustrates a material flow in a typical supply chain. It shows how material moves from supplier to customers' and at every stage a value is added to the material, whilst, a network generates value not just through goods, services and revenue, but also through knowledge. Knowledge becomes a medium of exchange in its own right, with success dependent on building a rich web of trusted relationships. The supply chain network proposed by Warkentin (Warkentin, Sugumaran et al. 2001) is extended to emphasise the creation of a value network for a complex e-business environment. In support of this trend towards e-networks, additional focus has been given to the implications on the value chain. Verna (Verna 2000b) states "the traditional view of value chain is outdated by the new enterprise model of the value network".Before the introduction of the Internet, the traditional view of the supply chain was that of inefficient communication 
and allocation. Information flowed in a linear fashion, either upstream or downstream. In addition, a further drawback was the lack of connection to one's customers, as organisations were forced to communicate through wholesalers, distributors and retailers. Dispersion of information beyond one link in the supply chain was inhibited through a lack of formal relationships. Furthermore, the "information flow through linkages was constrained due to a lack of standard data representation schemes, therefore, the sharing of information beyond immediate supply chain partners was impossible" (Warkentin, Sugumaran et al. 2001).

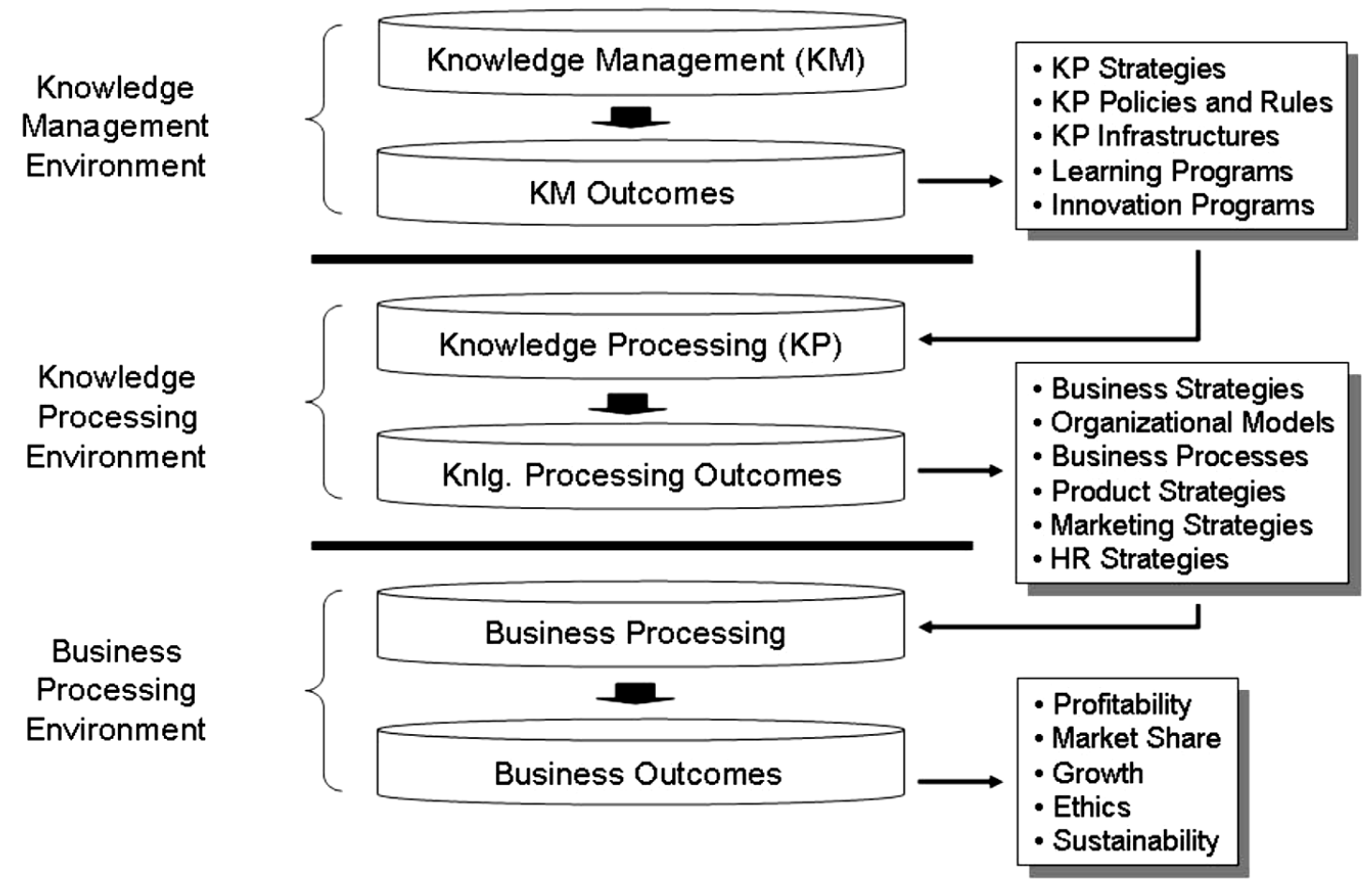

Figure 2. Knowledge management processes in the corporate(Joseph M. Firestone and Mark W. McElroy, 2005).

The traditional view of knowledge was to hoard it and If organisations were to share this valuable information, a competitive edge would be lost (Verna 2000b). However, the consensus among new economy organisations is to provide an open environment for the sharing of information. Organisations are encouraged to work "in close co-ordination to optimise the flow in the entire supply chain" (Warkentin, Sugumaran et al. 2001). The concept of the e-supply chain proposes a new relationship between suppliers, partners and customers as well as integration of processes, information systems and interorganisational problem solving (Manthou, Vlachopoulou et al. 2004). The e-supply chain is the backbone of a virtual network, linking each participant as one cohesive unit.

The chain comprises a series of value-added stages, starting with the supplier and ending with the consumer. The focus of the e-supply chain is on the bi-directional flow of information, each stage is a supplier to its adjacent downstream stage and a customer to its 
upstream stage. Each participant is therefore able to assume many roles within the supply chain, but the ultimate relationship comes down to a supplier and a customer role.

\section{KM AND CI TO ACHIEVE COMPETITIVE ADVANTAGE}

\section{1 . What is meant by competitive advantage?}

Concept of competitive advantage has a long tradition in the strategic management literature. Ansoff (1965) defined it thusly characteristics of unique opportunities within the field defined by the product-market scope and the growth vector. This is the competitive advantage. It seeks to identify particular properties of individual product markets which will give the firm a strong competitive position". NNN South (1981) defined competitive advantage as the "philosophy of choosing only those competitive arenas where victories are clearly achievable".

Porter (1985) states "competitive advantage grows fundamentally out of value a firm is able to create for its buyers that exceeds the firm's cost of creating it." He argued that a firm's ability to outperform its competitors lay in its ability to translate its competitive strategy into a competitive advantage. Competitive strategy entails positioning the firm favorably in an industry relative to competitors.

He confirmed that there are, in general, only two possible competitive advantages a firm may possess, a cost advantage or a differentiation advantage. Others, particularly proponents of the resource-based view of the firm (Barney, 1991; Conner, 1991), have extended the definition to include a wider range of possible advantages such as physical capital (Williamson, 1975), human capital (Becker, 1964), technological opportunities and learning (Teece, 1980; 1982; 1986), and organizational capital (Tomer, 1987).

\section{2. Synergy between $\mathrm{CI}$ and $\mathrm{KM}$ to obtain competitive advantage}

Knowledge management $(\mathrm{KM})$ is the process through which organizational performance is improved through better management of corporate knowledge. Its goal is to improve the management of internal knowledge processes so that all information required for corporate decisions can be made available and efficiently used. Competitive intelligence (CI) is a process for gathering usable knowledge about the external business environment and turning it into the intelligence required for tactical or strategic decisions. Both $\mathrm{KM}$ and $\mathrm{CI}$ systems are designed to enhance the information resources of an enterprise, but often target different information types and sources.

While CI is concerned with gathering information from the external environment to enable the company to gain competitive advantage (Williams, 2002), most investigation into $\mathrm{KM}$ has focused on capturing the knowledge stored within the minds of individual employees (Nidumolu, Subramani, \& Aldrich, 2001). Bagshaw (2000), Johnson (2000), Rubenfeld (2001), and Williams (2002) all focus on the use of KM for collecting, managing, and sharing internally generated knowledge.

The combination of effective KM and appropriate CI provide the right mix of the right information to the right decision maker at the right time. Certainly, these two fields are starting to blend into the same melting pot. However, each field has some unique qualities that differentiate it from the other. 


\section{3. The transition from the industrial to the knowledge-based thinking}

One of the most industrialized countries of the world that we still call it, is that the No other industry. We are witnessing a rapid transition from an industrial society to a knowledge society. Society Based on the increasing importance of knowledge as the fourth factor of production is based. Many of All products and services, research and development costs are exorbitant. Yet Production costs are much lower. Employ a large number of consultants in the form Investment advisory services are made by the company, the cost of waste Companies to a minimum. Investing in the knowledge base, as well as Consultants have prepared concurrently and that obviously cost a lot to create the but it Than their actual results to employer becomes cheaper. In fact, we still speak of the industrialized countries, much of our thinking is now, among the Industrial production is still based on the concepts of the early twentieth century and perhaps Nineteenth returns, but today the knowledge and the capacity to manage, create, and publish it, the main purpose Successful companies. This can be done with concepts like brand management, marketing Directly to customers and ... Interpreted. But this is only a visual transition from the industrial market Market knowledge is another characteristic of the economy is evolving (Yosefi et al, 2011).

\section{4. The emergence of the theory of competitive advantage}

The evolution of the concept of competitiveness, is a school science project. In this section Along with their concepts and theories of the respective schools and purposes will be provided. It is the first school classics. The advantage of the classical school of international trade. Will be considered by economists to be the only point in the economic activity of Terms of trade are considered two different geographical areas. In this section On the evolution of economic theory, economists seek to prove the competitive nature of the variables and criteria are. The most important element of classical thought, if minimum government intervention in economic affairs, especially trade International and motivated individual to achieve the balance of the public. Provide notions advantage Absolute (Smith) and comparative advantage (Ricardo), which was based on the cost of production, concomitant with Industrial Revolution, England had a positive effect on development. Smith 's theory An absolute boon for space - based free trade and lower manufacturing costs outside of Was the basis for the international division of labor(Daneshfard et al,2010).

\section{METHODOLOGY}

The overall objective of this study was to investigate the effect of knowledge management on competitive advantage in firms and Organizations in which the subject and purpose of the study is descriptive - correlation Is used. Data in this survey is based on questionnaires Literature adjusted for its validity in terms of academics and experts use To check the reliability of a sample of $n=30$ questionnaires distributed among the population SPSS software using Cronbach's alpha is measured. The Inventory Includes 22 items that 8 questions related to the independent variables (knowledge management) and for each One of the three dependent variables, five questions were designed. 


\section{1. Research hypotheses}

Major and minor premises of this research can be stated as follows:

1. There is a significant relationship between knowledge management and competitive advantage.

Minor hypotheses are as follows:

1.1. There is a Significant relationship between knowledge management and organizational performance.

1.2. There is a Significant relationship between knowledge management and customeroriented.

1.3. There is a significant relationship between knowledge management and product innovation.

\section{2. Data Analysis}

After reviewing the data from the questionnaires in order to test each of the first and second Primary and secondary research hypotheses, drawing tables contain the results of sampling size variables Tion was jointly independent of assumptions associated with the use of tables and tests D. Summers correlation, the correlation coefficient of the independent variable on the dependent was obtained as follows:

In the first step of the analysis was to examine the reliability of the sample The initial questionnaire was distributed and collected the questionnaire Cronbach's alpha for variables: chvariable the calculated results showed good reliability of the questionnaire.

Cronbach's alpha is calculated by the following:

Table 1. Computing Cronbach alpha.

\begin{tabular}{|c|c|c|}
\hline Scale & Cronbach's alpha & Corrected correlation \\
\hline organizational performance & $0 / 854$ & $0 / 385$ \\
\hline customer satisfaction & $0 / 741$ & $0 / 750$ \\
\hline innovation & $0 / 731$ & $0 / 758$ \\
\hline
\end{tabular}

Test results showed that the Pearson correlation coefficient between knowledge management as the independent variable and the dependent variable organizational performance as equals $78 \%$. Indicating a direct correlation between the two variables, and there is a significant relationship between the variables. Pearson test of knowledge management and innovation process:

Table 2. The first hypothesis test.

\begin{tabular}{|c|c|c|}
\hline $\mathrm{N}$ & Sig & $\mathrm{r}$ \\
\hline 115 & $0 / 000$ & $0 / 78$ \\
\hline
\end{tabular}


Test results showed that the Pearson correlation coefficient between management Knowledge as independent variables and customer satisfaction as the dependent variable equals $72 \%$. Indicating a direct correlation between the two variables, and there is a significant relationship between the variables.

Pearson correlation test results and customer knowledge management:

Table 3. The second hypothesis test.

\begin{tabular}{|c|c|c|}
\hline $\mathrm{N}$ & $\mathrm{Sig}$ & $\mathrm{r}$ \\
\hline 115 & $0 / 000$ & $0 / 72$ \\
\hline
\end{tabular}

Test results showed that the Pearson correlation coefficient between management Knowledge and innovation as an independent variable as the dependent variable equals Indicating a direct correlation between the two variables, and there is a significant relationship between the variables. Pearson test of knowledge management and product innovation:

Table 4. The third hypothesis test.

\begin{tabular}{|c|c|c|}
\hline $\mathrm{N}$ & Sig & $\mathrm{r}$ \\
\hline 115 & $0 / 000$ & $0 / 62$ \\
\hline
\end{tabular}

\section{DISCUSSION AND CONCLUSIONS}

Knowledge management as a key tool for the management of the new century, systematic and strategic Defined processes, acquisition, transfer and application of knowledge by individuals Organizations that promotes innovation, productivity and competitiveness and promote Moreover, contribute to problem solving, decision making, strategic planning, dynamiclearning Prevent mental decline as assets increase awareness of the organization and flexibility the increase.

Knowledge management as a mechanism to enable systematic organizing of the Knowledge will lead to better use of resources. Necessary when using this mechanism more It is obvious that organizations are aware of the effects and results of its use. Hence it in this paper we investigate the use of knowledge management in organizations' attempts. To so that a comprehensive analysis of the impact of knowledge management must be comprehensive view All parts of the organization, it requires taking into account the effects on the process of knowledge management Different parts of the organization.

The current study The first exploratory study included a review of the literature and conducting interviews to formulate hypotheses We then proceed to evaluate the hypotheses investigated by carrying out the survey. Analysis results Confirm the hypothesis. The research results indicate that knowledge management can include the subset of competitive 
advantage and customer satisfaction, organizational performance, and organizational innovation can make a significant impact.

\section{References}

[1] Adamides E. D., N. Karacapilidis, Technovation 26 (20-006) 50-56.

[2] Alavi M., D.E. Leidner, MIS Quarterly N25 (2001) 107-136.

[3] Aranda D. A., Molina-Fernandez L. M., Industrial management \& Data systems 102(5) (2002) 296.

[4] Bagshaw M., Industrial and Commercial Training 32 (2000) 179-183.

[5] Daneshfard, Allah Karam, Zakrei Mohammad, Effects of Knowledge Management Consulting engineers to strengthen the competitiveness of enterprises. (2010) Quarterly Rahbord yas.

[6] Deeds D. L., C. Hill, Journal of Business Venturing 11 (1996) 41-55.

[7] Jihene Chebbi Ghannay, Zeineb Ben Ammar Mamlouk, Synergy Between Competitive Intelligence and Knowledge Management - a key for Competitive Advantage, (2012), Journal of Intelligence Studies in Business.

[8] Motwani J., Gopalakrishna P., Subramanian R., " Source of knowledge acquisition by U.S. managers : An empirical analysis “, (2005), Idea Group Publishing, P. 16-19.

[9] Newman B., Conard D., The knowledge Management Forume. (1999).

Available at: www.km-forume.org

[10] Scarbrough H., International Journal of Manpower 24(5) (2003) 514.

[11] Shelfer K., "The Intersection of Knowledge Management and Competitive Intelligence: Smartcards and Electronic Commerce." Knowledge Management: (2004), Lesson Learned: What Works and What Doesn't. Eds. Michael E. D. Koenig and T. Kanti Srikantaiah. New Jersey: Information Today, Inc, 419-442

[12] Wong K. Y., Industrial management \& data system 105(3) (2005) 261-265.

[13] Yamin S., Gunasekaran A., Mavonda F. T., Technovation 19(8) (1999) 507-518.

[14] Yosefi Ehsan, Fizi Jaafar, Mohammad Soliamani, Evaluation of the impact of knowledge management on innovation (Among managers and employees of technology companies based in the University of Science and Technology Park, Quarterly ingenuity in Humanities, 3 (2011). 